\title{
Performance Analysis of a Compressor Leading Edge without Pressure Spike at High Subsonic Speed
}

\author{
Henning Lang ${ }^{1}$, Takashi Goto ${ }^{2}$, Daisuke Sato $^{2}$, Dai Kato ${ }^{2}$ and Peter Jeschke ${ }^{1}$ \\ ${ }^{1}$ Institute of Jet Propulsion and Turbomachinery, RWTH Aachen University \\ Templergraben 55, 52062 Aachen, Germany \\ ${ }^{2}$ IHI Corporation, Japan
}

\begin{abstract}
This paper describes an experimental investigation on a state-ofthe-art compressor airfoil with three different leading edges at high subsonic flow conditions. In addition to a conventional circular and elliptical geometry which possess curvature discontinuities at the blend points, a continuous curvature leading edge is studied. The investigation considers the performance at design incidence, as well as the impact of off-design incidences.

Pressure spikes near the leading edge can lead to early transition associated with higher profile losses. Goodhand and Miller [1] showed that in low subsonic conditions the avoidance of curvature discontinuities can diminish pressure spikes and therefore reduce the profile losses and enlarge the working range. In this paper, measurements are conducted to assess the potential of this concept for a high-pressure jet engine compressor airfoil operated at high subsonic conditions $\left(M_{1}=0.7, R e_{\mathrm{d} / 2}=20,000\right)$. The results show that, at design incidence, the total pressure loss coefficient of the continuous curvature leading edge reduces by up to $15.4 \%$ compared to the circular leading edge and by up to $3.1 \%$ for the elliptical geometry. At off-design incidence, the reduction can be up to $40.2 \%$ at maximum positive incidence under consideration.
\end{abstract}

$\begin{array}{ll}\text { NOMENCLATURE } \\ A V D R & \text { Axial velocity density ratio } \\ b & \text { Chord length } \\ c & \text { Absolute velocity } \\ d & \text { Leading edge thickness } \\ D_{\text {spike }} & \text { Spike diffusion factor } \\ i & \text { Incidence angle } \\ h & \text { Blade height } \\ H_{12} & \text { Shape factor } \\ l & \text { Leading edge length } \\ \dot{m} & \text { Mass flow rate } \\ M & \text { Mach number } \\ M P & \text { Measuring plane } \\ n & \text { Direction normal to surface } \\ t & \text { Pitch } \\ p & \text { Pressure } \\ R e & \text { Reynolds number } \\ s & \text { Profile contour coordinate } \\ T & \text { Temperature } \\ t & \text { Pitch }\end{array}$$$
[\mathrm{m}]
$$$$
[-]
$$$$
\text { [deg] }
$$$$
\text { [m] }
$$$$
[-]
$$$$
[\mathrm{m}]
$$$$
[\mathrm{kg} / \mathrm{s}]
$$$$
[-]
$$

Presented at International Gas Turbine Congress 2019 Tokyo, November 17-22, Tokyo, Japan

Review Completed on, September 17, 2020

$\begin{array}{lll}T u & \text { Turbulence intensity } & {[\%]} \\ u & \text { Velocity in flow direction } & {[\mathrm{m} / \mathrm{s}]} \\ v & \text { Velocity perpendicular to flow direction } & {[\mathrm{m} / \mathrm{s}]} \\ w & \text { Velocity in spanwise direction } & {[\mathrm{m} / \mathrm{s}]} \\ x & \text { Axial direction } & {[\mathrm{m}]} \\ x^{\prime} & \text { Coordinate in chord direction } & {[\mathrm{m}]} \\ y & \text { Pitchwise direction } & {[\mathrm{m}]} \\ z & \text { Spanwise direction } & {[\mathrm{m}]} \\ \alpha & \text { Flow angle (pitchwise) } & {[\mathrm{deg}]} \\ \gamma & \text { Heat capacity ratio } & {[-]} \\ \gamma & \text { Flow angle (spanwise) } & {[\mathrm{deg}]} \\ \Delta & \text { Difference } & \\ \delta_{1} & \text { Displacement thickness } & {[\mathrm{m}]} \\ \delta_{2} & \text { Momentum thickness } & {[\mathrm{m}]} \\ \delta_{3} & \text { Energy thickness } & {[\mathrm{m}]} \\ \kappa & \text { Curvature } & {[1 / \mathrm{m}]} \\ v & \text { Kinematic viscosity } & {\left[\mathrm{m}^{2} / \mathrm{s}\right]} \\ \omega & \text { Total pressure loss coefficient } & {[-]} \\ \rho & \text { Density } & {\left[\mathrm{kg} / \mathrm{m}^{3}\right]}\end{array}$

Subscripts

$\begin{array}{ll}1 & \text { Inlet } \\ 2 & \text { Outlet } \\ \text { cont.curv. } & \text { Continuous curvature leading edge } \\ \text { ax } & \text { Axial } \\ \text { circular } & \text { Circular leading edge } \\ \text { corr } & \text { Corrected } \\ \text { elliptical } & \text { Elliptical leading edge } \\ \text { is } & \text { Isentropic } \\ \text { max } & \text { Maximum } \\ \text { min } & \text { Minimum } \\ \text { norm } & \text { Normalized } \\ \text { PS } & \text { Pressure side } \\ \text { s } & \text { Static } \\ \text { SS } & \text { Suction side } \\ \mathrm{t} & \text { Total }\end{array}$

\section{INTRODUCTION}

Efficiency improvement has been the main driver in compressor development for decades. Even though the further potential for improvement has decreased over the years due to a better understanding of the compressor flow, increasing fuel costs justify further research on advancements. Nowadays, multiple disciplines and aspects are considered, especially the product life cycle, and maintenance, repair and operations (MRO) aspects are assessed. For years, the development of new airfoils neglected the potential of optimized leading edges. Instead, circular leading edges were used since they are easy to manufacture and resistant to erosion or other damages. It was 
assumed that sharp leading edges offer lower loss coefficients at design incidence but are prone to stall at off-design incidences due to the resulting strong pressure gradient at the leading edge. Although CFD methods have been established, the leading edge geometry was still of minor importance. The reason for this is that compressor optimization tools often neglect flow transition, and thus the leading edge seems to have little effect on the losses [2].

In the early 1960s, Carter [3] reported investigations into different compressor leading edge radii and showed that the smallest radius offered the widest operating range because of smaller local pressure spikes in the vicinity of the leading edge. In the early 1990s, Walraevens and Cumpsty [4] demonstrated that an elliptical leading edge with an ellipse aspect ratio of 1.89:1 performs better when compared to a circular leading edge because of avoided laminar separation. This observation was confirmed by Wheeler et al. [5] who compared an elliptical leading edge with an ellipse aspect ratio of 3:1 with a circular leading edge. They found that the total pressure loss coefficient was $32 \%$ lower for the elliptical leading edge. Goodhand and Miller [1,2] presented further investigations at the same low-speed compressor test rig. They concluded that local pressure spikes, as shown in Fig. 1, and the associated decelerated flow can lead to laminar separation bubbles. As a result, they defined a criterion for spike-induced flow separation based on the spike diffusion factor

$$
D_{\text {spike }}=\frac{c_{\max }-c_{\min }}{c_{\max }} \geq 0.1 \text {, }
$$

where $c_{\max }$ represents the maximum inviscid surface velocity of the spike and $c_{\min }$ denotes the minimum velocity at the bottom of the inviscid spike (Fig. 1). Furthermore, they designed a leading edge without curvature discontinuity which showed better resistance to spike generation. As a result of the suppressed spike, they called the design a spikeless leading edge. The difference in the isentropic Mach number distribution is illustrated in Fig. 1.

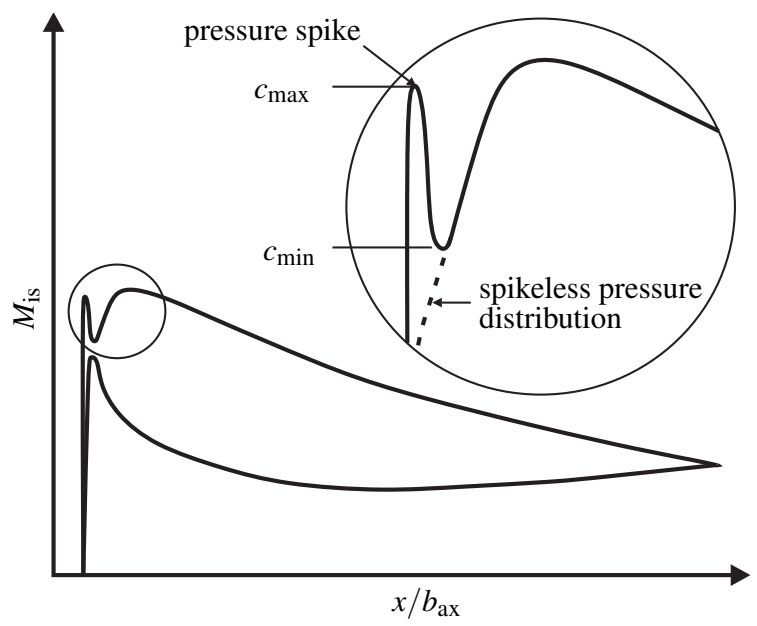

Fig. 1: Scheme of a profile $M_{\text {is }}$-distribution with and without pressure spike.

The idea of a continuous curvature leading edge was further pursued by Zhang et al. [6] who carried out a CFD optimization of a turbine airfoil. They reduced the total pressure loss by $10 \%$. Song et al. [7] carried out RANS and LES simulations for circular, elliptical and continuous curvature compressor leading edge geometries. Under consideration of the simulation results, they tried to give a theoretical explanation for the pressure spike occurrence due to a curvature discontinuity. Based on the incompressible boundary-layer equations for curved surfaces and employing dimensional analysis, they deduced a relation between curvature $\kappa$, density $\rho$, streamwise velocity $c$ and pressure gradient perpendicular to the surface $\partial p / \partial n$ from the momentum equation in the direction normal to the surface:

$$
\frac{1}{\rho} \frac{\partial p}{\partial n}=\kappa c^{2}
$$

The curvature $\kappa$ is defined as the reciprocal of the local radius of curvature and positive for a convex surface. Song et al. then considered two adjacent points which are located just upstream and downstream of the curvature discontinuity (Fig. 2). As an example, it is assumed that upstream of the discontinuity the curvature is strong, which is typically the case for circular leading edges. Just behind the discontinuity, the curvature is zero. Furthermore, it is assumed that the variation of free-stream pressure in streamwise direction is small compared to the normal pressure gradient $\partial p / \partial n$ in the boundary layer. Figure 2 illustrates this scenario. Starting from the stagnation point, the streamwise velocity $c$ increases along the leading edge, accompanied by an increase in pressure gradient $\partial p / \partial n$ at constant curvature $\kappa>0$. Due to the resulting acceleration of the near-wall flow, the wall pressure decreases rapidly until the curvature discontinuity is reached. Just behind the curvature discontinuity, the pressure gradient $\partial p / \partial n$ becomes zero, and thus the wall pressure corresponds to the free-stream pressure. Taking into account the assumption that the free-stream pressure does not change over the curvature discontinuity, this results in a jump of the surface pressure in streamwise direction. This finally forms the descending part of the pressure spike in the isentropic Mach number distribution.

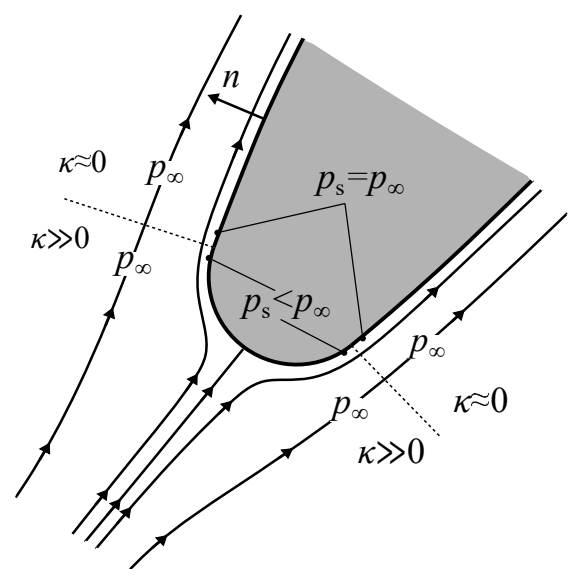

Fig. 2: Scheme of the effect of curvature discontinuity near a leading edge.

All work which has been mentioned above studied the influence of leading edges at low subsonic flow conditions. Based on the work of Walraevens and Cumpsty [4], Tain and Cumpsty [8] carried out measurements and studied high subsonic flow along a flat airfoil with a circular leading edge. They concluded that the Mach number $M$, Reynolds number $R e$, and turbulence intensity $T u$ are additional parameters that affect the leading edge performance. Increasing the inlet Mach number leads to a rapidly growing boundary layer downstream of the leading edge which results in larger loss coefficients. With increasing Reynolds number and turbulence intensity, the leading edge separation bubble which occurs becomes smaller, leading to sharper streamline curvature. This results in larger pressure spikes and local Mach number and therefore higher loss coefficients. Similar trends were identified by Goodhand [2], who carried out theoretical considerations and CFD parameter studies for compressor airfoils.

In this work, a state-of-the-art high-pressure compressor profile was equipped with three leading edges, namely a circular, an elliptical and an optimized leading edge. The optimized leading edge is designed as polynomial function with continuous curvature across 
the blend points of the leading edge and the profile. This study evaluated the different geometries experimentally, in terms of performance at design and off-design incidence at high subsonic conditions. To the authors' knowledge, no other published work exists concerning experimental investigations into continuous curvature leading edges at high subsonic conditions. As the works of Tain and Cumptsy [8] and Goodhand [2] suggest, these flow conditions with high Mach number and Reynolds number will enlarge the effects that have been observed at incompressible conditions. For this reason, this paper aims to verify that the continuous curvature leading edge concept also performs better at high subsonic conditions - in terms of the total loss coefficient and working range - than the conventional leading edge geometry.

The leading edge geometries considered in this paper are illustrated in Fig. 3. The blend points between leading edge, pressure side, and suction side, as well as the profile contour are the same for each configuration. In contrast to other publications (e.g. [1,7]), this leads to different leading edge and chord lengths. The benefit of this design is that the elliptical leading edge encloses the circular leading edge and the continuous curvature leading edge contour surrounds the elliptical leading edge. In terms of MRO aspects, influences of leading edge deformations or repair methods can be assessed. $\mathrm{Li}$ [9] recently presented a similar approach. Fig. 4 provides the

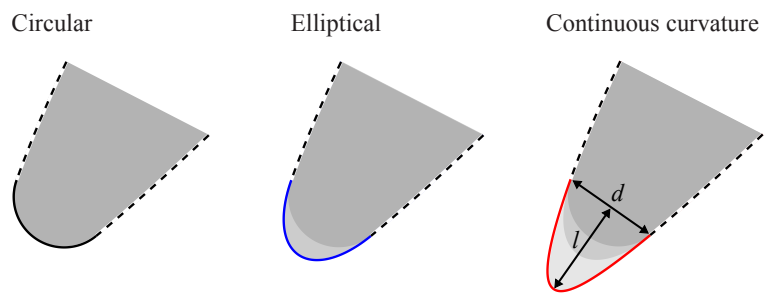

Fig. 3: Leading edge geometry variations

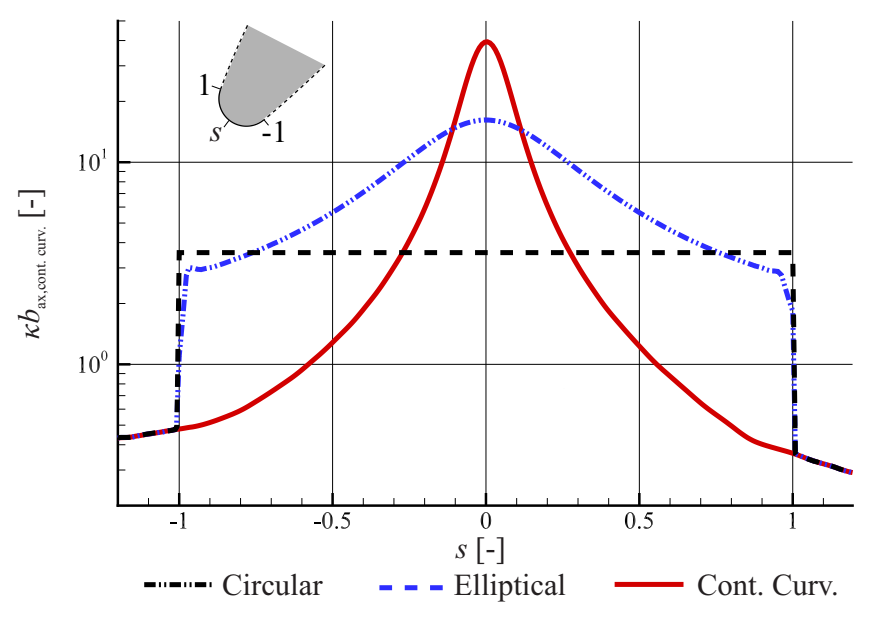

Fig. 4: Curvature distribution along the leading edges

curvature distribution for the three leading edge geometries. The blend points are located at $s=-1$ (suction side) and $s=1$ (pressure side). Both circular and elliptical leading edges have a curvature discontinuity at the blend points, whereas the curve of the continuous curvature leading edge merges with the profile surface without an abrupt jump. The wedge angle of the leading edge at the blend points is about $30^{\circ}$ and the ratio of the elliptical leading edge is $1.8: 1$. The aspect ratios of the leading edges defined by the ratio of leading edge length $l$ and maximum leading edge thickness $d$ are as follows: $(l / d)_{\text {cont.curv. }}=1,(l / d)_{\text {elliptical }}=0.6,(l / d)_{\text {circular }}=0.4$.

\section{EXPERIMENTAL SETUP}

\section{Linear cascade wind tunnel}

The tests were carried out in the institute's linear cascade wind tunnel which is shown in Fig. 5. The rig is designed for measurements on compressor cascades [10,11], as well as turbine cascades [12]. In recent years, the wind tunnel was used to quantify the influence of manufacturing deviations on profile aerodynamics (e.g., [11]) and to provide detailed measurements for CFD model optimization.

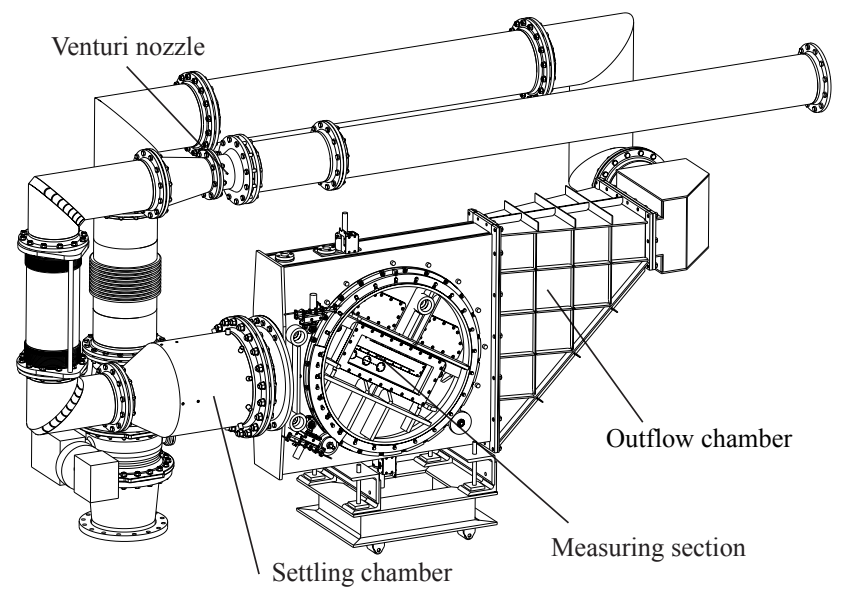

Fig. 5: Linear cascade wind tunnel

A 2 MW electrical motor powers a multi-stage radial compressor that provides compressed air to the wind tunnel at a mass flow rate of up to $\dot{m}=5.5 \mathrm{~kg} / \mathrm{s}$ and total pressure of up to $p_{t}=1.8 \cdot 10^{5} \mathrm{~Pa}$. At the end of the supply pipe, a Venturi nozzle is mounted to measure the mass flow. A settling chamber first homogenizes and reduces the flow turbulence. Through a passive turbulence grid, turbulence is generated in order to set a well-defined turbulence intensity of $T u=2.6 \%$ in the measuring section. After passing the turbulence grid, a convergent nozzle accelerates the flow and changes the crosssection from circular to rectangular. The dimensions of the inlet sections are $200 \mathrm{~mm}$ x $80 \mathrm{~mm}$ and the distance between nozzle end and center airfoil leading edge is $800 \mathrm{~mm}$. The measuring section (Fig. 6) consists of the airfoil cascade, traversable probes upstream and downstream the cascade and wall pressure taps. It is located in the middle of the test rig and placed between two turnable round sidewalls. This allows a variation in the inlet angle of between $40^{\circ} \leq \alpha_{1} \leq 160^{\circ}$. Since the inlet channel is fixed to the rig casing, turning the test section would lead to different distances between airfoils and sidewalls in the pitchwise direction. For this reason, the top and bottom of the inlet channel can be moved horizontally and the number of airfoils in the cascade can be varied in order to ensure sufficient flow periodicity between the two blade passages around the center airfoil. After passing the measuring section, a sudden enlargement of the cross-section in the spanwise direction generates constant backpressure on the test section. The outflow casing ends in discharge lines which, depending on the operating point, end in the exhaust (open circuit) or at the inlet of the air supply compressor (closed loop operation). This flexibility allows for independent Reynolds number and Mach number variation.

\section{Instrumentation}

Fig. 6 gives an overview of the measuring planes in the test section. Inflow conditions are measured in measuring plane MP1a. A 2Dtraversing unit allows traverses with five-hole, Pitot or triple hot-wire probes in $\mathrm{y}$ - (pitchwise) and z- (spanwise) direction. The static pressure for the calculation of the inlet Mach number $M_{1}$ and Reynolds number $R e_{1}$ is captured by 19 wall pressure taps in measuring plane $M P 1 d$ with spacing of $\Delta y / t=0.06$. Furthermore, this measuring 
plane and $M P 2$ are used to calculate the non-periodicity index according to [13] for periodicity evaluation. The cascade outflow of the center passages can be traversed by a combined Pitot-five-hole probe or a triple hot-wire probe in three dimensions between $1<x / b_{\mathrm{ax}} \leq 2$ and $0.06 \leq z / h \leq 0.94$. Surface pressure measurements are taken at the profile surfaces adjacent to the center airfoil, so that wake measurements behind the center airfoil are not affected by pressure taps. Due to manufacturing limitations, it was not possible to place pressure taps on the leading edges. The first pressure tap is therefore located at the blend point of the suction and pressure side. In addition to the measuring planes, the total pressure and total temperature are measured in front of the turbulence grid in the settling chamber by three Pitot probes and three resistance temperature devices, respectively.

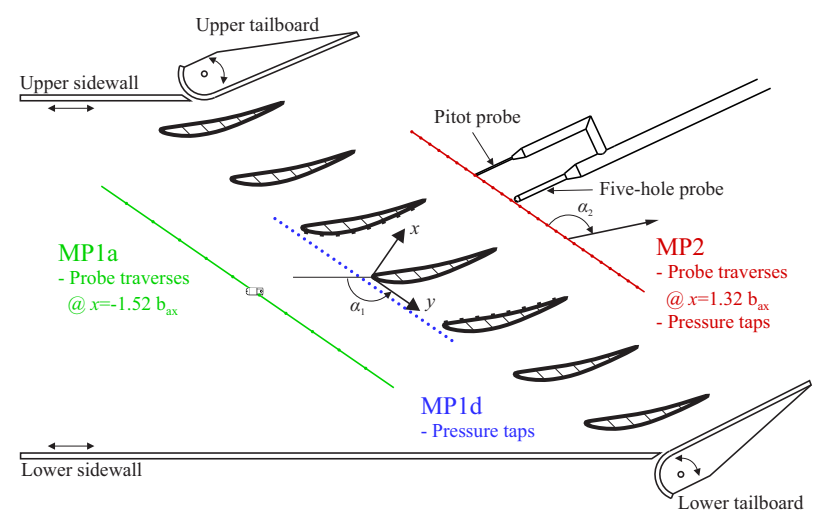

Fig. 6: Measuring section with measuring planes

For all pressure measurements, despite the inlet and outlet pressure measured by the Pitot probes in MP1 $a$ and $M P 2$, a psi Pressure Systems Rackmount Pressure Scanner 98RK-1 was used with a pressure range of 0.69 bar. The inlet total pressure $p_{\mathrm{t} 1}$ and outlet total pressure $p_{\mathrm{t} 2}$ were measured by high-precision Mensor differential (CPR2550, 0.8 bar range) and absolute (CPT 6100, 1.8 bar range) pressure transducers, respectively. All differential transducers used the ambient pressure as reference. It was measured by a Mensor CPR2550 barometer. The five-hole probes were evaluated using a lookup-table approach and a correction method as described in [14].

The hot-wire measurements were conducted using individually designed triple wire probes manufactured by Imotec Messtechnik with $9 \mu \mathrm{m}$ platinum-tungsten wires and a Dantec Streamline Pro CTA bridge. The probe was calibrated in the institute's free jet wind tunnel using a mass flow density calibration approach [15]. The overheat temperature was set to $250{ }^{\circ} \mathrm{C}$, the sampling rate for all measurements was $250 \mathrm{kHz}$ and the measuring time was $4 \mathrm{~s}$, resulting in 1,000,000 samples per measurement. Measurement uncertainty was assessed as described in [16] and is of the magnitude of $\Delta T u= \pm 0.07 \%$.

\section{Airfoils and test parameters}

As described in the introduction, the measuring object is a profile of a modern high-pressure compressor for aero engines. Three different leading edge geometries were tested. Only the leading edge section up to the blend points was varied, while the rest of the profile remained the same for all configurations (Fig. 3 and Fig. 4). During manufacturing, special care was taken to ensure that manufacturing deviations did not affect the aerodynamics. Geometrical inspection and roughness measurements were conducted to ensure that geometry deviations were within limits and that the surface roughness was lower than the hydraulic smooth limit defined by Schlichting [17]. The measured discrepancy in blade geometry of the center airfoil was lower than $\pm 0.01 \mathrm{~mm}$ between the three configurations. The chord length $b$ is about $64 \mathrm{~mm}$, which is the maximum possible length in the cascade. This leads to a relatively low aspect ratio, so it was necessary to verify that the flow can be assumed to be two-dimensional at blade midspan. Fillets are placed at bottom and top of the airfoil to reduce the corner vortices.[18]

In the measuring campaign presented here, only one operating point was considered, defined by $M_{1}=0.7$ and the Reynolds number based on half of the leading edge thickness $R e_{\mathrm{d} / 2}=(c \cdot d) /(2 v)=20,000$. The variables $c$ and $v$ denote the flow velocity and the kinematic viscosity. The total temperature was set to $T_{t}=46{ }^{\circ} \mathrm{C}$ and the inlet turbulence intensity at $M P 1 a$ was $T u_{1}=2.6 \%$. In total six incidences were studied, $i=-5^{\circ},-3^{\circ}, 0^{\circ}, 1.5^{\circ}, 3^{\circ}$ and $5^{\circ}$, with design inflow angle set to $i=0^{\circ}$. Wake traverses in $M P 2$ were conducted at $x=1.32 b_{\mathrm{ax}}$ behind the center airfoil.

\section{Calculation of total pressure loss coefficient}

It was found that the probe in MPla, which measures the total pressure $p_{\mathrm{t} 1}$, can affect the cascade flow and the wake behind the cascade. It was therefore decided to remove the probe during the traverses in $M P 2$. However, for the calculation of the total pressure loss coefficient

$$
\omega=\frac{p_{\mathrm{t} 1}-p_{\mathrm{t} 2}}{p_{\mathrm{t} 1}-\widetilde{p_{\mathrm{s} 1}}}
$$

it is necessary to determine $p_{\mathrm{t} 1}$, especially because operating point fluctuations and drifts can have a considerable impact on the loss coefficient. One possible approach is to measure the difference in total pressure between the settling chamber and MPla before and after a traverse. The total pressure in MPla during the traverse can then be derived from the settling chamber total pressure and the previously determined offset. This method works fine if only the differential comparison is of interest. To reliably determine the absolute loss coefficient, a modified version of the method presented in [19] is used, which is illustrated in Fig. 7. Since the Pitot probe in MPla is extracted during the wake traverse in $M P 2$, the settling chamber total pressure is used as $p_{\mathrm{t} 1}$. However, the settling chamber pressure is measured upstream of the turbulence grid and thus, pressure losses between settling chamber and MPla have to be taken into account. It is assumed that pressure loss through the cascade only occurs in the wake region. The offset $\Delta p_{\mathrm{t}}=\overline{p_{\mathrm{t} 1}-p_{\mathrm{t} 2}}$ is therefore calculated for both sides outside the wake (PS : $-0.5 \leq y / t \leq-0.25$, SS : $0.25 \leq y / t \leq 0.5)$. The offset in the wake region is interpolated linearly. Finally, the settling chamber total pressure $p_{\mathrm{t} 1}$ is corrected by the offset $p_{\mathrm{t} 1 \text {, corr }}=p_{\mathrm{t} 1}-\Delta p_{\mathrm{t}}$. Due to the high flow velocity and relatively short distance between the settling chamber and five-hole probe in $M P 2$, the operating point fluctuations are similar over the entire cascade. The difference $p_{\mathrm{t} 1, \mathrm{corr}}-p_{\mathrm{t} 2}$ therefore, is not affected by the operating point fluctuations anymore. Moreover, potential differences in total pressure level between both passages around the center airfoil as a result of imperfect periodicity are eliminated with this method.

The static pressure $\widetilde{p_{\mathrm{s}} 1}$ in equation 3 is calculated by the areaaverage $(\sim)$ over one pitch of the static wall pressure in MPld. For averaged values of $\omega$, the outlet total pressure $p_{\mathrm{t} 2}$ is mass flow averaged over one pitch $\left(^{-}\right)$.

$$
\bar{\omega}=\frac{\overline{p_{\mathrm{t} 1, \mathrm{corr}}}-\overline{p_{\mathrm{t} 2}}}{\overline{p_{\mathrm{t} 1, \mathrm{corr}}}-\widetilde{p_{\mathrm{s} 1}}}
$$

In this paper, the total pressure loss coefficient is always normalized by the loss coefficient of the continuous curvature leading edge at $i=0^{\circ}$

$$
\begin{gathered}
\omega_{\text {norm }}=\frac{\omega}{\omega_{\text {cont.curv. }, \mathrm{i}=0^{\circ}}} \\
\bar{\omega}_{\text {norm }}=\frac{\bar{\omega}}{\bar{\omega}_{\text {cont.curv. }, \mathrm{i}=0^{\circ}}} .
\end{gathered}
$$




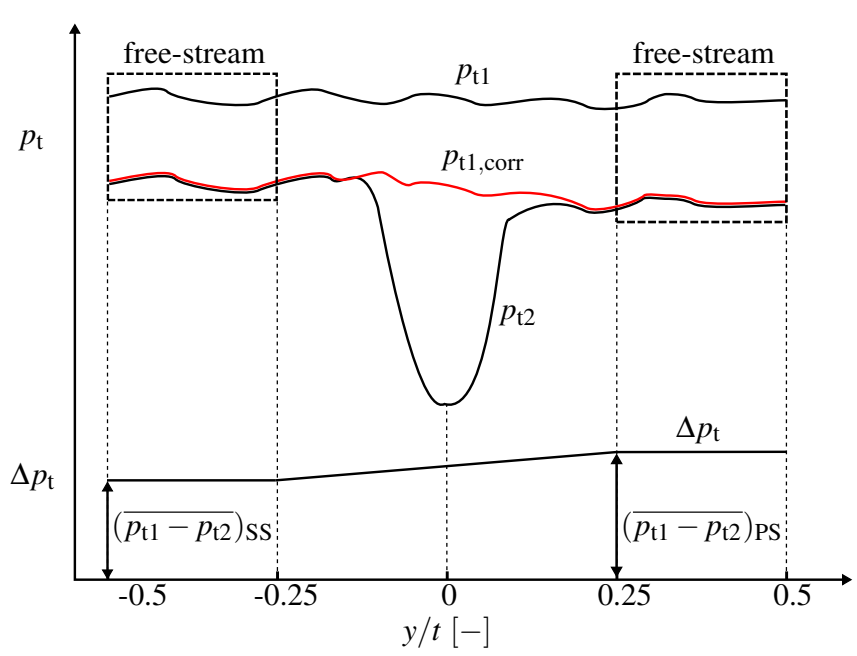

Fig. 7: Correction of inlet pressure

\section{RESULTS}

\section{Proof of periodicity and 2D-flow at midspan}

Special attention was given to the correct setting of periodic flow conditions for each incidence. The periodicity was quantified by the difference in total pressure loss coefficient $\omega_{\text {norm }}$ and flow angle in pitchwise direction $\alpha_{2}$ in the free-stream region around the center airfoil. For all leading edge geometries and incidences, the difference was below half of the measurement uncertainty $\left(\left|\alpha_{2,-0.5 \mathrm{t}}-\alpha_{2,+0.5 \mathrm{t}}\right| \leq 0.5^{\circ}\right.$ and $\left.\left|\omega_{\text {norm },-0.5 t}-\omega_{\text {norm },+0.5 \mathrm{t}}\right| \leq 0.014\right)$.

Due to the low aspect ratio, the flow at midspan might be disturbed by secondary flows, like corner vortices. The Axial Velocity Density Ratio

$$
A V D R=\frac{\int_{-0.5 t}^{0.5 t} \rho_{2} c_{2} \cos \left(\alpha_{2}-90^{\circ}\right) \mathrm{dy}}{\int_{-0.5 t}^{0.5 t} \rho_{1} c_{1} \cos \left(\alpha_{1}-90^{\circ}\right) \mathrm{dy}}
$$

is given in Fig. 8 for all incidences and leading edge geometries investigated. While the AVDR is similar between all configurations for negative incidences up to $i=0^{\circ}$, the AVDR tends to be slightly higher in the case of the continuous curvature leading edge at positive incidences, followed by the elliptical leading edge. The AVDR increases continuously with increasing incidence angle, resulting in a difference of $12 \%$ between minimum and maximum incidence. It is well known that an $A V D R>1$ leads to lower diffusion and therefore lower loss coefficients compared to the two-dimensional flow case $(A V D R=1)[20]$. In the context of this investigation however, the effect can be disregarded, because only the relative difference between the leading edge geometries is of interest.

In order to evaluate the two-dimensionality of the flow more precisely, the flow angle in spanwise direction $\gamma_{2}$ is shown in Fig. 9 for the largest incidence studied in this work and for the freestream location $(y / t=0.5)$. Taking the measurement uncertainty into account, the flow angle at midspan $(z / h=0.5)$ is around $\gamma_{2}=0^{\circ}$, indicating two-dimensional flow. Towards the sidewalls, the flow angle slightly changes, but remains almost zero between $z / h=0.25$ and $z / h=0.75$ taking into account the measuring accuracy.

As a final proof of two-dimensionality, oil flow visualization and two-dimensional five-hole probe traverses were conducted for $i=-5^{\circ}, 0^{\circ}$ and $5^{\circ}$. As already indicated by the AVDR, the case of continuous curvature leading edge at $i=5^{\circ}$ was the most critical case in respect of the two-dimensionality of the flow. Fig. 10 shows oil flow visualization of the suction side of the center airfoil. Endwall secondary flow can be detected by the blue color at the bottom and top of the airfoil. The vortices expand up to $z / h=0.37$ and $z / h=0.76$ towards midspan. The cause of the asymmetry between

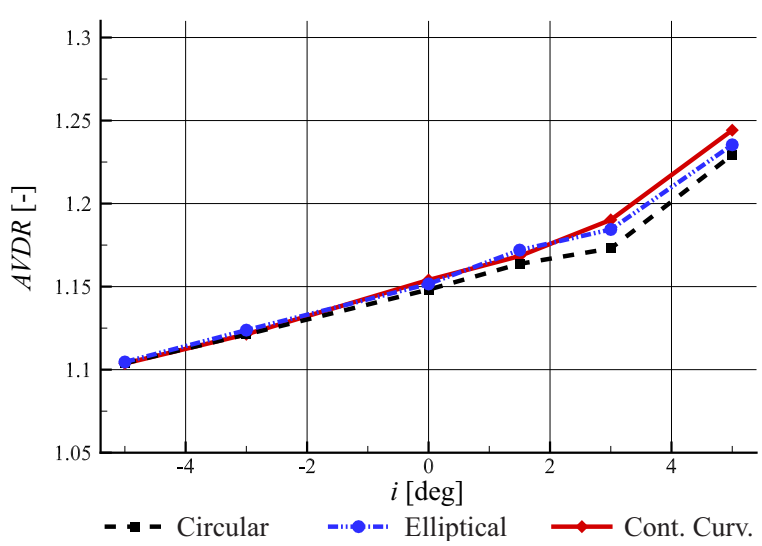

Fig. 8: Axial velocity density ratio

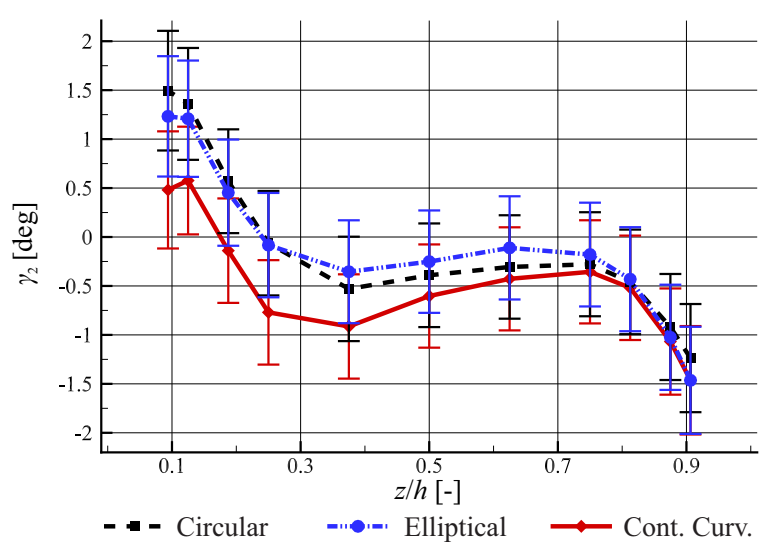

Fig. 9: Spanwise flow angle $\gamma_{2}$ at incidence $i=5^{\circ}$ and $y / t=0.5$

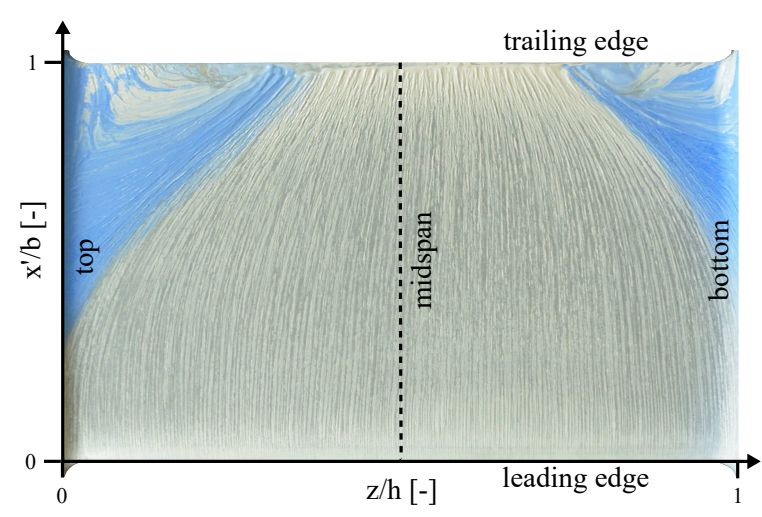

Fig. 10: Oil flow visualization of suction side flow structures (continuous curvature leading edge) at $i=5^{\circ}$

the top and bottom is unknown. It is assumed that slight leakage flow between the blade tip and sidewall may cause this asymmetry.

Fig. 11 provides local total pressure loss coefficient information. High loss coefficients characterize endwall secondary flow and the profile wake. Even though the flow structure changes slightly from $z / h=0.5$ to $z / h=0.37$, it is nearly constant for the other direction towards $z / h=0.63$. The other two leading edge geometries showed similar secondary flow behavior in the outlet measurements. For this reason, $i=5^{\circ}$ was selected as the maximum incidence to be investigated in this study. 


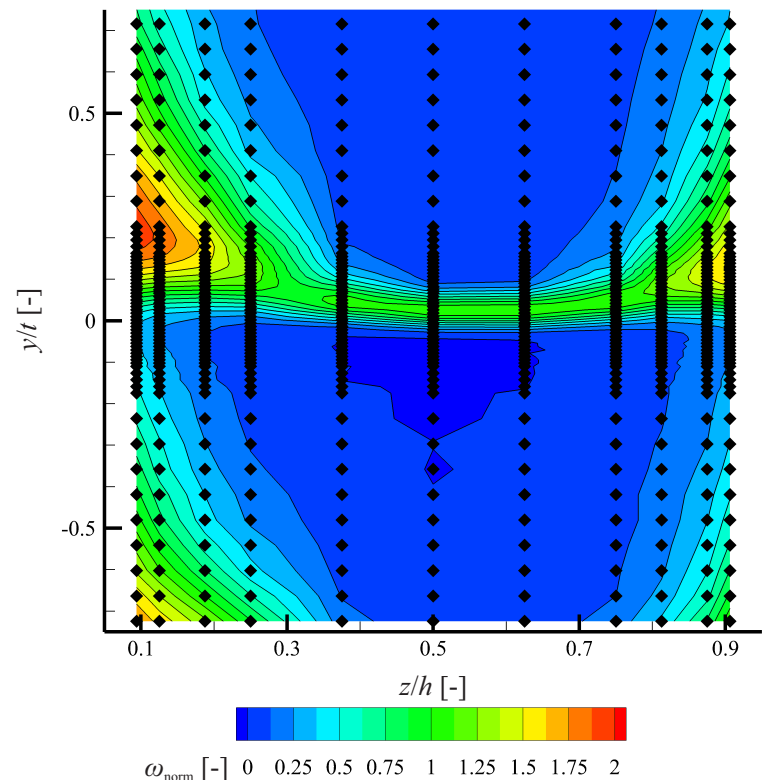

Fig. 11: Flow field behind the center airfoil with continuous curvature leading edge in $M P 2$ at $i=5^{\circ}$

\section{Loss polar}

The main objectives of the new leading edge are the reduction of losses and an improvement in working range in terms of the incidence range, as defined by the maximum allowed loss coefficient. The averaged parameters for the loss coefficient $\bar{\omega}_{\text {norm }}$ and the outlet flow angle $\overline{\alpha_{2}}$ are therefore the most important values for assessing the different leading edge geometries. The loss polars of all three leading edge geometries investigated in this paper are shown in Fig. 12a.

The outlet flow is measured with the combined Pitot-five-hole probe which is sketched in Fig. 6. The total pressure measurements of the Pitot probe and five-hole probe were compared during the entire test campaign and the difference was found to be lower than the measuring uncertainty of the Pitot probe. The five-hole probe is therefore used in order to obtain the flow angle and the total pressure at the same time. Since the measuring uncertainty of the five-hole probe is about ten times higher than for the Pitot probe, the uncertainty of the Pitot probe is used to calculate the uncertainty of the averaged loss coefficient.

All three loss polars show a well-known behavior with minimum losses at design inflow angle and increasing loss coefficients towards positive and negative incidences. As expected, the profile with continuous curvature leading edge has the lowest loss coefficients, followed by the elliptical leading edge profile. Based on Fig. 12b, which shows the differences in loss coefficient

$$
\Delta \bar{\omega}=\frac{\bar{\omega}-\bar{\omega}_{\text {cont.curv }}}{\bar{\omega}_{\text {cont.curv. }}}
$$

of elliptical and circular leading edges compared to the optimized one, the magnitude of the loss reduction can be quantified. At design incidence, the loss coefficient of the continuous curvature leading edge is reduced by $15.4 \%$ compared to the circular leading edge and by $3.1 \%$ for the elliptical leading edge. At maximum positive incidence, the difference increases to $40.2 \%$ and $20.6 \%$, respectively. At negative incidences, the loss coefficients show higher sensitivity and the discrepancy further increases (circular: $45.7 \%$, elliptical: $21.3 \%$ ). The working range of the new continuous curvature leading edge enlarges significantly, e.g., the incidence range is twice as wide as for the circular leading edge, assuming the same loss limits.

Fig. 13 shows the influence of incidence on the outlet flow angle $\alpha_{2}$. Each polar is corrected by its on-design value because of the a)

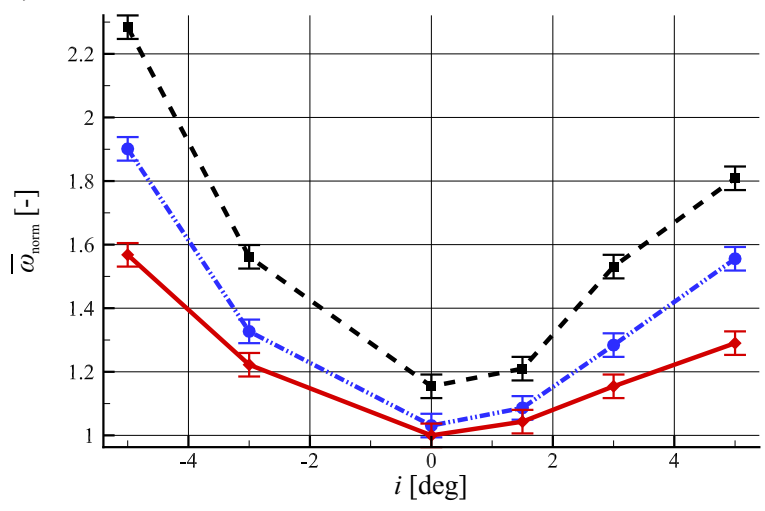

b)

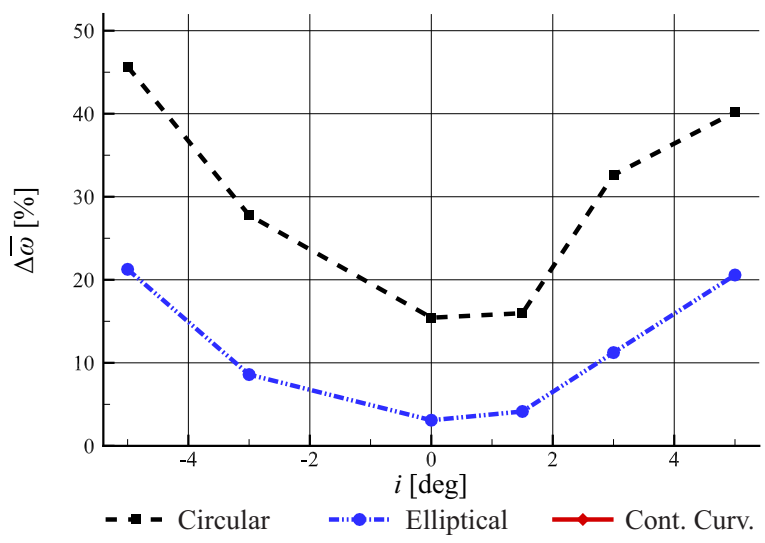

Fig. 12: Loss polar for all three leading edge geometries (a) and deviation from continuous curvature leading edge loss (b)

large measuring uncertainty of $\Delta \alpha= \pm 0.5^{\circ}$. As such, only relative comparisons are possible. The increase in incidence is accompanied by an increase in flow angle for all three leading edges, which means that the deviation angle increases. In the case of the continuous curvature leading edge, the outlet flow angle increases only by $\Delta \alpha_{2}=$ $\alpha_{2, \max }-\alpha_{2, \min }=1^{\circ}$ for the incidence range considered in this study, whereas the elliptical and circular leading edges lead to increases of $\Delta \alpha_{2}=1.7^{\circ}$ and $\Delta \alpha_{2}=2.1^{\circ}$, respectively. This overall trend fits in well with the improved operating range, although the flow angle hardly changes for negative incidences, while the losses increase significantly. The reduction of outlet angle-dependence on flow incidence can be of great benefit to multi-stage compressors because the flow misalignment is reduced in subsequent stages, and so the losses in these stages also decrease.

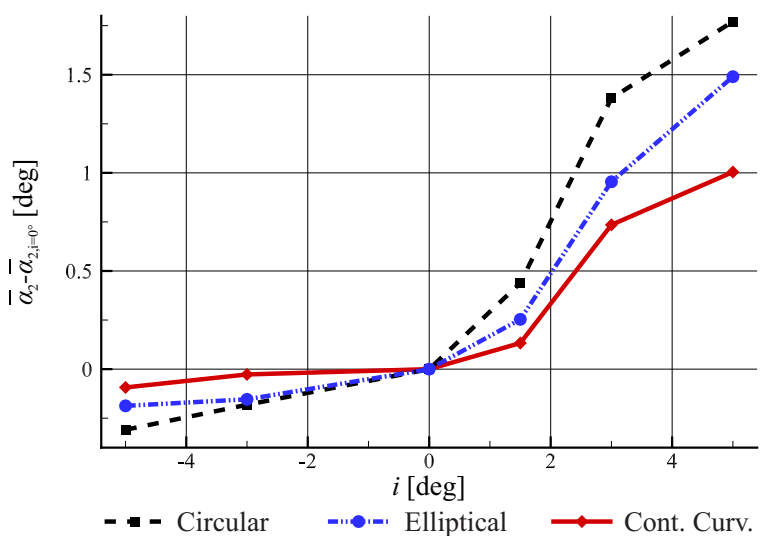

Fig. 13: Relative development of the outlet flow angle 
a) $i=-5^{\circ}$

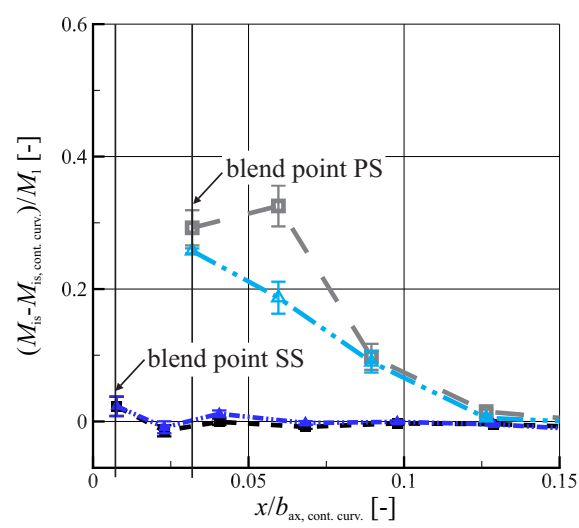

d) $i=1.5^{\circ}$

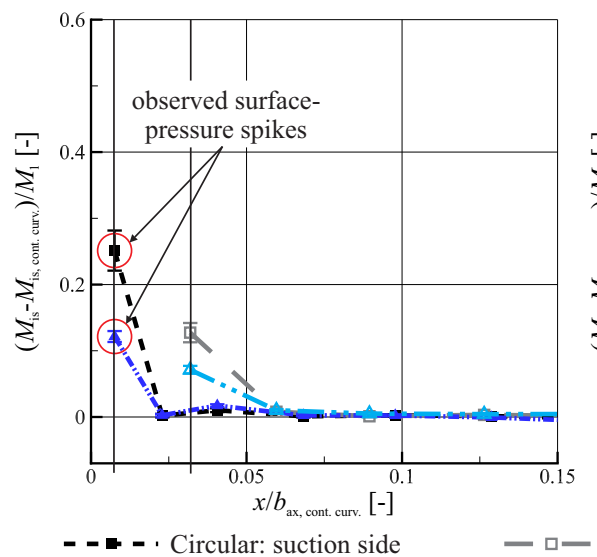

b) $i=-3^{\circ}$

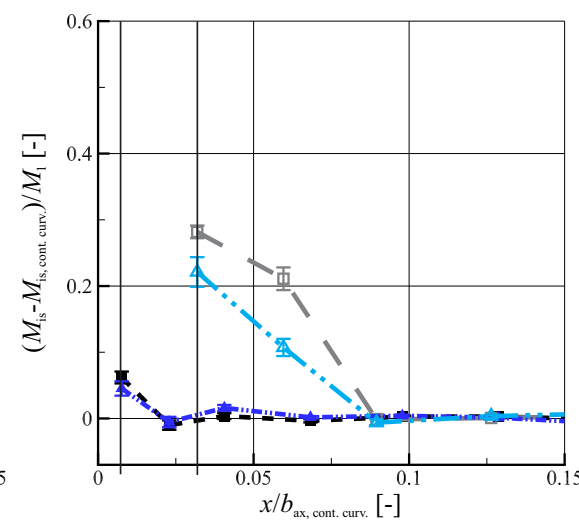

e) $i=3^{\circ}$

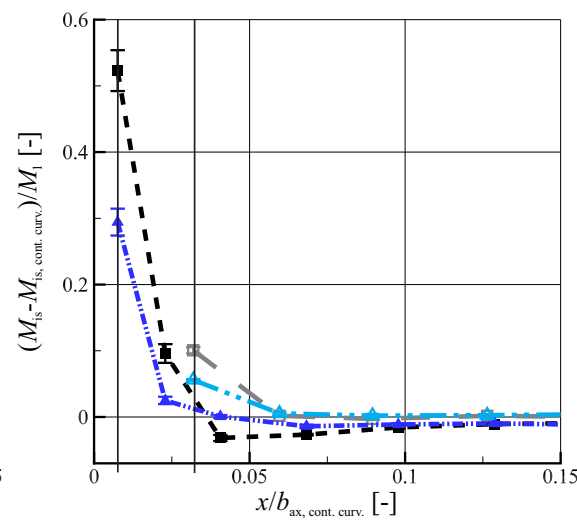

$x / b_{\text {ax, cont curr. }}[-]$ c) $i=0^{\circ}$

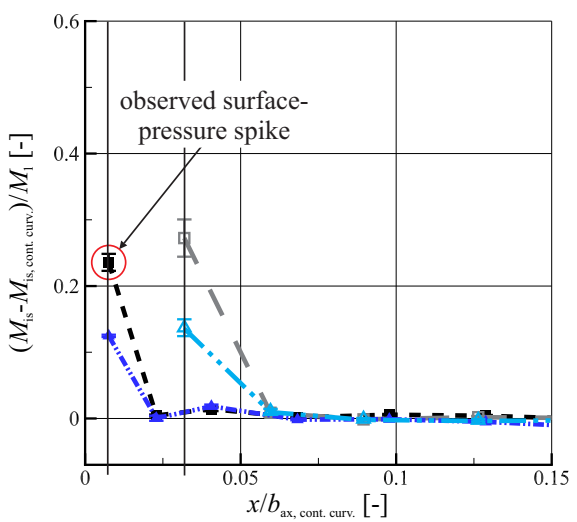

f) $i=5^{\circ}$

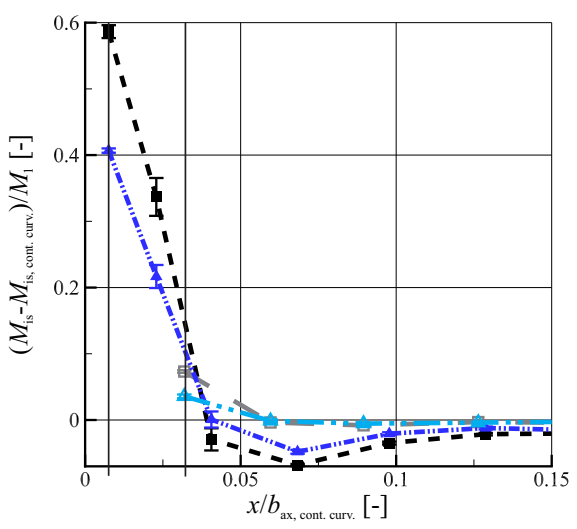

Fig. 14: Deviation of the profile isentropic Mach number of circular and elliptical leading edge in relation to the continuous curvature leading edge

\section{Surface pressure distribution}

Goodhand and Miller [1] identified pressure spikes near the blend point of the leading edge and profile surface as the main cause for the leading edge dependent losses. Since the investigated profile is used in a state-of-the-art compressor, it is not possible to provide absolute values in terms of isentropic Mach number distribution. However, the following has been observed in the absolute isentropic Mach number distribution $M_{\mathrm{is}}\left(x / b_{\mathrm{ax}}\right)$ near to the leading edge:

- Indications for pressure spikes, with a local maximum followed by a local minimum in the isentropic Mach number just behind the leading edge, were observed on the suction side for the circular leading edge at $i=0^{\circ}$ and $1.5^{\circ}$ and for the elliptical leading edge at $i=1.5^{\circ}$ on the suction side. The maxima are marked in Fig. 14 with red circles.

- For the elliptical and circular leading edge at higher incidences $\left(i=3^{\circ}\right.$ and $\left.5^{\circ}\right)$, the maximum isentropic Mach number is measured at the first profile pressure tap. There is no local minimum velocity in the vicinity of the leading edge on the suction side. It is therefore not possible to distinguish between pressure spike and profile pressure distribution.

- For the continuous curvature leading edge and positive incidence, the velocity at the first profile pressure tap is always lower than for the pressure taps downstream, and therefore pressure spike could be indentified. At $i=5^{\circ}$, the velocity at the first and second profile pressure tap is almost the same.
- For negative incidences, the isentropic Mach number only decreases in flow direction for the pressure side and increases for the suction side.

To study the differences in the profile pressure distributions, the percentage deviation from the isentropic Mach number distribution of the continuous curvature leading edge profile $\left(M_{\text {is }}-M_{\text {is,const.curv. }}\right) / M_{1}$ is used here. The isentropic Mach number $M_{\text {is }}$ is calculated by

$$
M_{\mathrm{is}}=\sqrt{\frac{2}{\gamma-1}\left[\left(\frac{p_{\mathrm{t} 1, \mathrm{corr}}}{p_{\mathrm{s}}}\right)^{\frac{\gamma-1}{\gamma}}-1\right]} .
$$

Fig. 14 shows the resulting distributions for the suction and pressure sides of the elliptical and circular leading edge airfoils. In all cases, the $M_{\text {is }}$-distributions only differ near the leading edge by up to $x / b_{\mathrm{ax}}=0.15$. Starting at high negative incidences (Fig. 14a-b), the configurations almost exclusively differ in their pressure side distribution. At $i=-5^{\circ}$, flow decelerates more strongly behind the elliptical leading edge compared to the continuous curvature leading edge. The deceleration around the circular leading edge is lower just behind the blend point up to $x / b_{\mathrm{ax}, \text { cont.curv. }}=0.06$, followed by a much higher deceleration than for the other two geometries. Considering the absolute pressure distribution where a nearly flat level is visible in this region, this might indicate the end of a large laminar separation bubble. Towards increasing incidences, the discrepancies in the pressure side pressure distribution vanish and hardly change 
a) $i=-5^{\circ}$

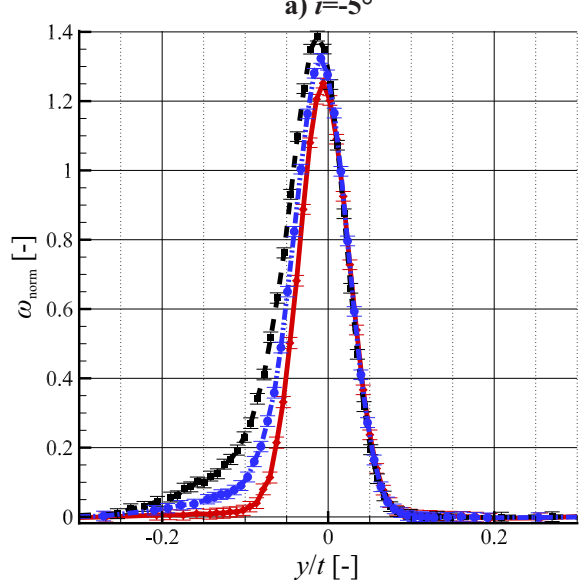

d) $i=1.5^{\circ}$

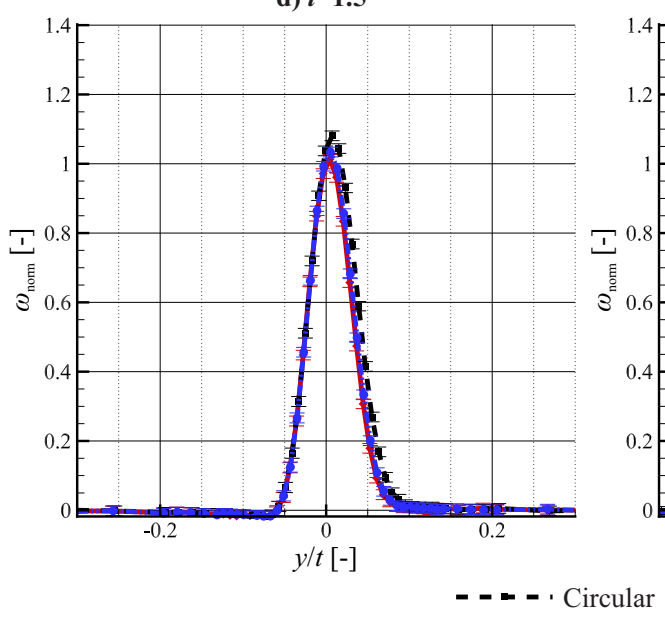

b) $i=-3^{\circ}$

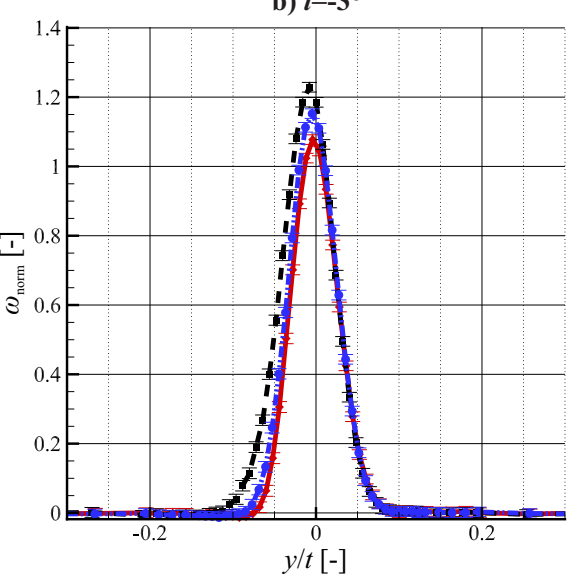

e) $i=3^{\circ}$

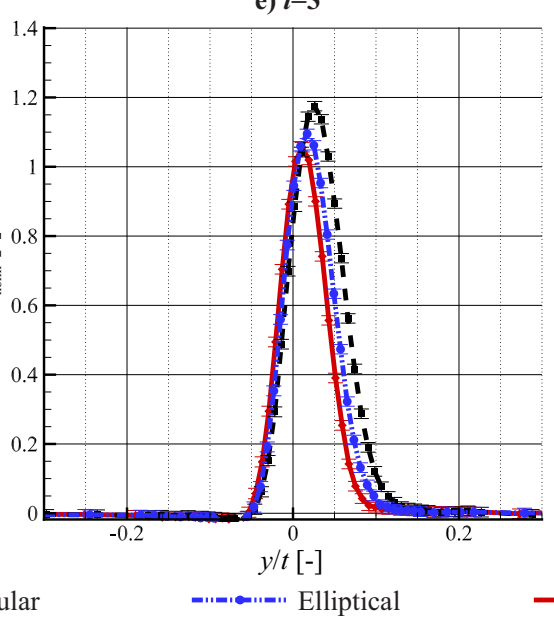

c) $i=0^{\circ}$

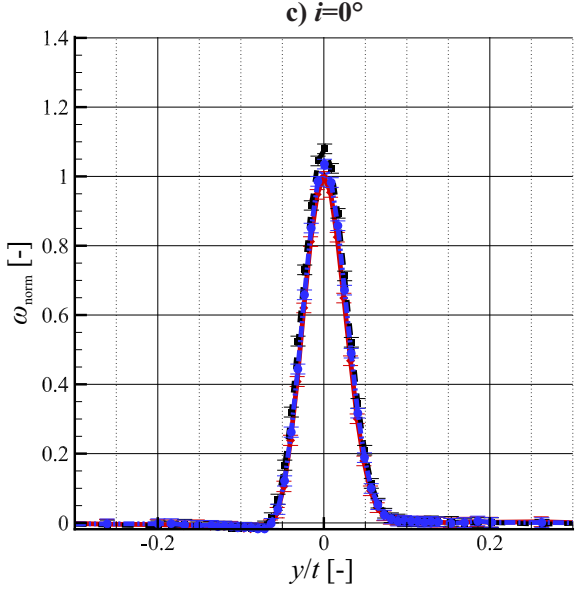

f) $i=5^{\circ}$

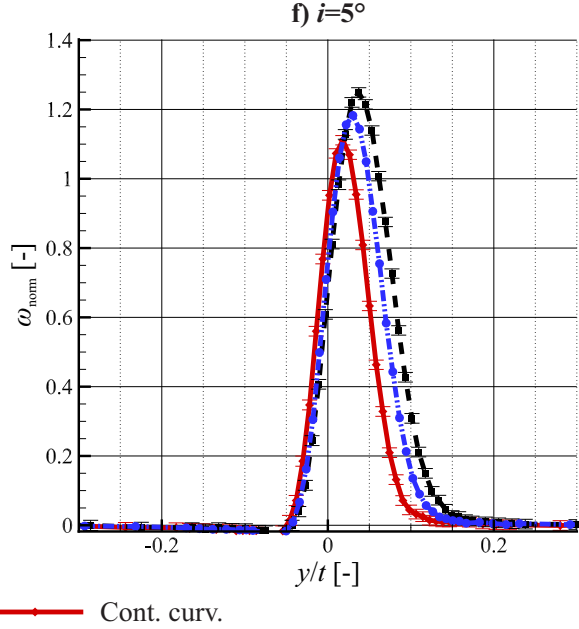

Fig. 15: Midspan wake traverses at $x / b_{a x}=1.32$

at all for positive incidences (Fig. 14d-f). For the suction side, deviations increase with increasing incidence. As mentioned above, the absolute surface pressure distribution at design incidence reveals that a pressure spike on the suction side occurs near the circular leading edge (red circle), while the other two geometries show a steady acceleration of the flow in the vicinity of the leading edge. For the moderate incidence of $i=1.5^{\circ}$, a pressure spike is also measured for the elliptical leading edge (red circle), and the magnitude of the spike of the circular geometry increases at the first profile pressure tap. Because of the lack of available surface pressure information around the leading edges, it is not possible to state whether the pressure spike increases or moves downstream. The measured isentropic Mach number at $i=3^{\circ}$ and $5^{\circ}$ near the blend point further increases for all configurations, but the spikes at the circular and elliptical leading edge are no longer visible because they merge into the decelerated part of the suction surface. It is worth mentioning that for $i=3^{\circ}$ and $5^{\circ}$ the suction surface isentropic Mach number distribution of the circular and elliptical leading edge in the region of $0.05 \leq x / b_{\text {ax } \text {,cont.curv. }} \leq 0.13$ is lower than the isentropic Mach number of the continuous curvature leading edge. A similar trend was also observed by Goodhand and Miller [1] and Song et al. [7].

\section{Wake evaluation}

The small dimensions of the cascade airfoils and the high subsonic flow conditions make it difficult to use measuring techniques inside the cascade because of manufacturing limitations for the profile pressure taps or blockage effects of probes. Probe traverses in $M P 2$ do not affect the flow through the cascade and are therefore used to compare the different leading edge geometries. Midspan traverses in MP2 are shown in Fig. 15. The local loss coefficient is used to eliminate the influence of the pressure fluctuations and to make the traverses comparable, since the absolute pressure might change between test days. The position $y / t=0$ marks the wake minimum of the continuous curvature leading edge case at $i=0^{\circ}$. Unlike the measurement uncertainty for the averaged loss coefficient, the measurement uncertainty given here is based on the five-hole probe. Furthermore, Fig. 16 provides the calculated displacement thickness $\delta_{1}$, momentum thickness $\delta_{2}$, energy thickness $\delta_{3}$ and shape factor $H_{12}$, which are calculated for both sides of the wake minimum separately. The definitions used here employ the compressible formulation and are given in equation 10-13.

$$
\begin{aligned}
\delta_{1} & =\left|\int_{0}^{ \pm t / 2}\left(1-\frac{\rho(y) c(y)}{(\overline{\rho c})_{\text {free-stream }}}\right) \mathrm{d} y\right| \\
\delta_{2} & =\left|\int_{0}^{ \pm t / 2} \frac{\rho(y) c(y)}{(\overline{\rho c})_{\text {free-stream }}}\left(1-\frac{c(y)}{\bar{c}_{\text {free-stream }}}\right) \mathrm{d} y\right| \\
\delta_{3} & =\left|\int_{0}^{ \pm t / 2} \frac{\rho(y) c(y)}{(\overline{\rho c})_{\text {free-stream }}}\left(1-\frac{c(y)^{2}}{\bar{c}_{\text {free-stream }}^{2}}\right) \mathrm{d} y\right| \\
H_{12} & =\frac{\delta_{1}}{\delta_{2}}
\end{aligned}
$$

In line with Fig. 7, the index "free-stream" denotes the averaged values of $\rho$ and $c$ between $y / t=-0.5 \ldots-0.25$ and $y / t=0.25 \ldots 0.5$. Due to the small wake width, the uncertainty in the calculation of the parameters is quite significant. Even small deviations in the displacement or momentum thickness can have 
a) Circular leading edge, suction side

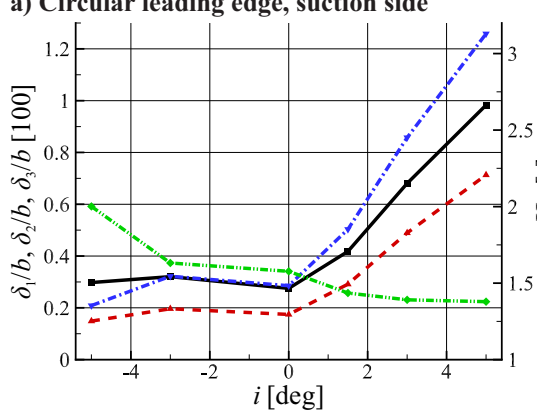

d) Circular leading edge, pressure side

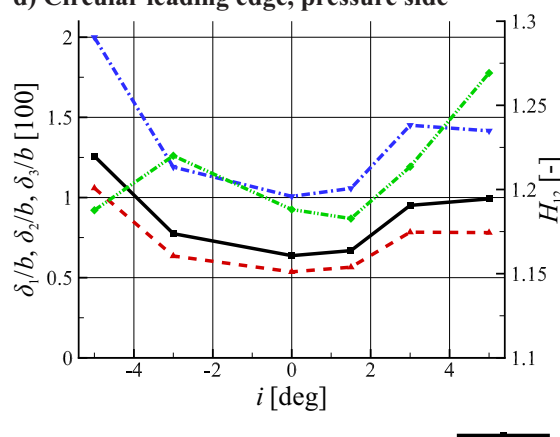

b) Elliptical leading edge, suction side

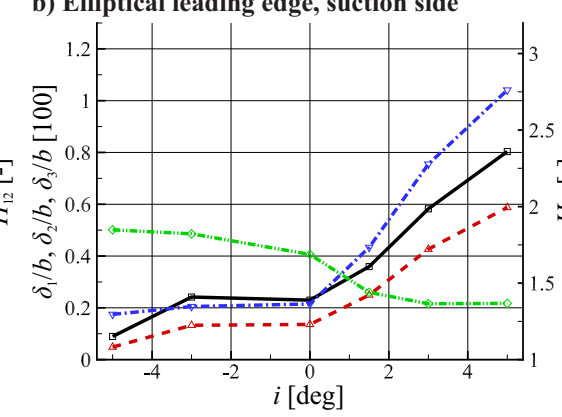

e) Elliptical leading edge, pressure side

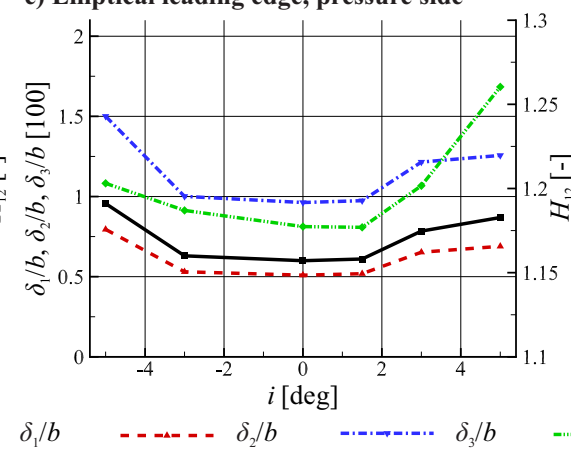

c) Cont. curvature leading edge, suction side

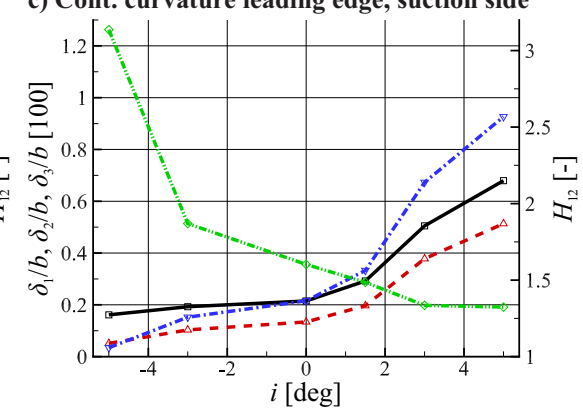

f) Cont. curvature leading edge, pressure side

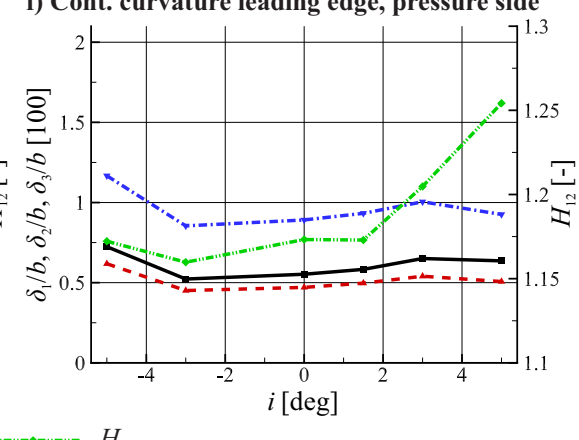

Fig. 16: Boundary layer thicknesses measured in the wakes at $x / b_{a x}=1.32$

a substantial impact on the shape factor $H_{12}$. Nevertheless, the parameters are used to derive general trends.

At design incidence (Fig. 15c), the wakes of all geometries are identical in width but differ in depth, resulting in higher loss coefficients for the circular and elliptical leading edge. The boundary layer parameters (Fig. 16) therefore, are also very similar between all geometries. Towards negative incidences, the pressure side wake part thickens, while the suction side part does not change despite an increase in depth. The shape factor $H_{12}$ of the suction side seems to indicate a significant change for the continuous curvature leading edge at $i=-5^{\circ}$, but this is probably due to the uncertainty in the calculation of the parameter. At $i=-3^{\circ}$, the pressure side wake thickness of the circular leading edge increases much more strongly than the elliptical and continuous curvature leading edges which are of the same magnitude. The situation changes for $i=-5^{\circ}$, where the shape of the circular and elliptical leading edge wakes changes significantly. The thickness of both wakes changes by a factor of 3.5 when compared to the design incidence, whereas for the continuous curvature leading edge, the wake thickness just rises by a factor of two. The shape factor $H_{12}$ of the circular and elliptical leading edge geometry tends to increase towards negative incidence, indicating that the boundary layer state on the profile surface has slightly changed. Even though the wake shape changes significantly, the wake minimum barely shifts towards the pressure side. In the case of positive incidences, the pressure side wake thickness of the continuous curvature leading edge hardly changes, although the wake minimum shifts in the suction side direction and towards higher maximum loss coefficients. On the contrary, the pressure side wake thickness of the circular and elliptical leading edge is constant between $i=0^{\circ}$ and $1.5^{\circ}$ and slightly increases for higher incidences. Up to $i=3^{\circ}$, the surface side wake thickness of all configurations increases at the same magnitude as the pressure side wake thickness does for negative incidences. In contrast to $i=-5^{\circ}$, the shape of the surface side wake part does not change at $i=5^{\circ}$, resulting in lower loss coefficients compared to the corresponding negative incidence (see Fig. 12). It is worth to mention that the suction side shape factor $H_{12}$ at positive incidences is almost identical between the different leading edges. Furthermore, the suction side energy thickness $\delta_{3}$ of all configurations increases continuously with increasing positive incidence, which is in good agreement to [1]. Between $i=0^{\circ}$ and $-3^{\circ}$, however, the energy thickness remains almost constant, which differs from Goodhand and Miller's measurements, where a constant decrease was observed.

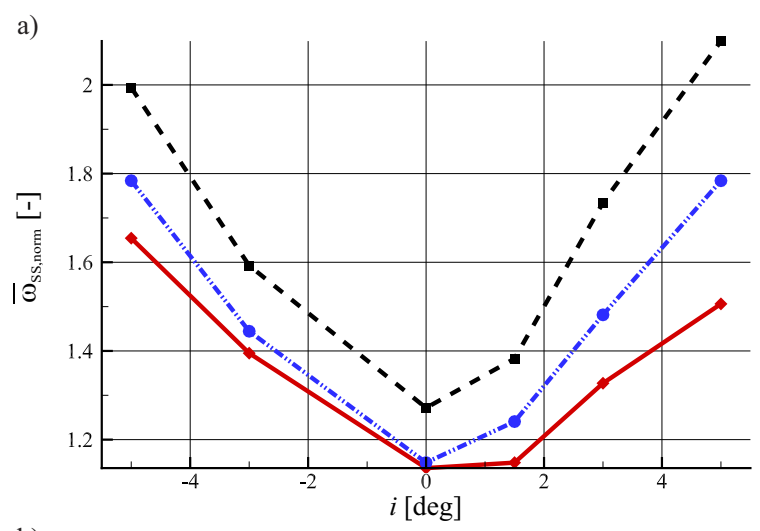

b)

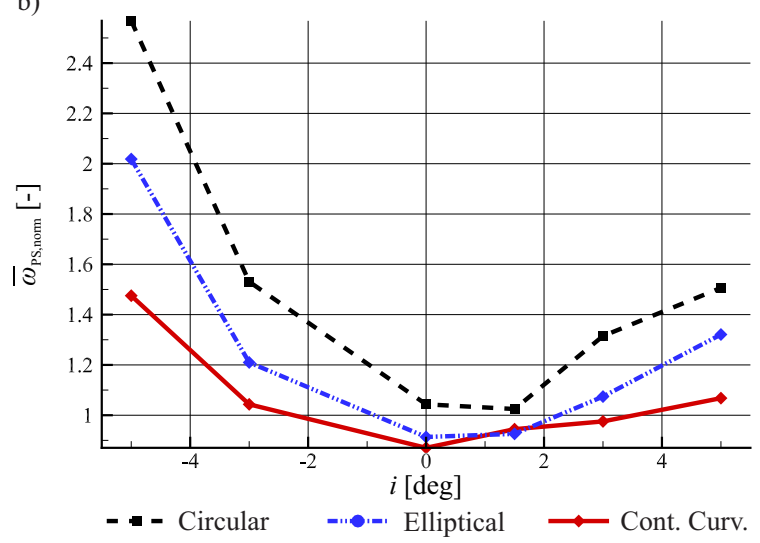

Fig. 17: Loss breakdown into suction (a) and pressure side (b) total pressure loss coefficient 
In addition to the figures discussed above, Fig. 17 shows the breakdown of averaged loss coefficients for the pressure and suction side. The losses are normalized by the overall continuous curvature leading edge loss at $i=0^{\circ}$ in order to preserve the relationship between pressure and suction side losses. The pressure side loss primarily affects the overall loss at negative incidences. Only for $i=-5^{\circ}$ do the pressure side loss coefficients of the circular and elliptical leading edge exceed the suction side loss coefficients. The suction side losses influences the overall loss at both positive and negative incidence. In contrast to the pressure side losses, the suction side losses exhibit different behavior for each geometry. While the negative incidence loss coefficients for the continuous curvature leading edge exceed the corresponding loss coefficients at positive incidence, the situation is reversed for the circular leading edge. The elliptical leading edge shows symmetric loss behavior.

\section{Hot-wire measurements}

In addition to five-hole probe traverses, hot-wire measurements were conducted in $M P 2$ for the circular and continuous curvature leading edge at $i=0^{\circ}$ and $5^{\circ}$. These measurements aim to study the change in turbulence due to the leading edge geometry. Since no dominant periodic flow phenomena was identified in the measurements, simple Reynolds decomposition $c=\langle c\rangle+c^{\prime}$ is applied to the data to distinguish between steady component $\langle c\rangle$ and fluctuation $c^{\prime}$. Fig. 18 gives an overview of the measured turbulence intensity

$$
T u=\frac{\sqrt{\frac{1}{3}\left(\left\langle u^{\prime 2}\right\rangle+\left\langle v^{\prime 2}\right\rangle+\left\langle w^{\prime 2}\right\rangle\right)}}{\langle c\rangle} .
$$

The variables $u^{\prime}, w^{\prime}$ and $v^{\prime}$ in equation 14 represent the fluctuating velocities in mean flow direction, spanwise direction, and perpendicular to the first two mentioned. The components thus do not correspond to the directions of the $x-y$-coordinate system. The newly introduced coordinate system allows a more descriptive representation of the Reynolds stresses along a streamline.

The turbulence intensity behind the circular leading edge profile exceeds the continuous curvature leading edge by a factor of 1.22 at $i=0^{\circ}$ and 1.34 at $i=5^{\circ}$. While the course on the pressure surface side is the same for both profiles and incidences up to $y / t \leq-0.05$, the suction surface side shows different behavior. At $i=0^{\circ}$, the turbulence intensity starts rising at $y / t=0.1$ for both incidences. On the contrary, at $i=5^{\circ}$, the course of the circular leading edge already starts to increase at $y / t=0.15$, whereas for the continuous curvature leading edge it still begins at $y / t=0.1$. This corresponds well with the wakes measured by the five-hole probe (Fig. 15). Besides this, it is noticeable that - in contrast to the pressure measurements the top of the curve at $y / t=0$ is not continuously curved for all cases, despite the continuous curvature profile at design incidence. The curves at $i=5^{\circ}$ possess a flat level between $y / t=-0.035$ and $y / t=0$, and the curve of the circular leading edge at $i=0^{\circ}$ even has an additional local maxima at $y / t=0.014$.

To study this in detail, Reynolds stresses for both leading edges at $i=0^{\circ}$ are plotted in Fig. 19. The different magnitudes of the normal stresses $\left\langle u^{\prime} u^{\prime}\right\rangle,\left\langle v^{\prime} v^{\prime}\right\rangle$ and $\left\langle w^{\prime} w^{\prime}\right\rangle$ in the free-stream result from the nozzle upstream of the test section. The turbulence is generated upstream of the nozzle in the settling chamber through a turbulence grid. The convergent nozzle leads to flow acceleration, and according to the linear rapid distortion theory, the lateral normal stresses $\left\langle v^{\prime} v^{\prime}\right\rangle$ and $\left\langle w^{\prime} w^{\prime}\right\rangle$ increase, while the component in flow direction $\left\langle u^{\prime} u^{\prime}\right\rangle$ decreases [21]. This results in anisotropic turbulence, which is still present downstream of the cascade. In the free-stream region, the Reynolds stresses of continuous curvature leading edge and circular leading edge behave very similar, so that the accuracy of the measured data is confirmed. According to the Reynolds stress balance for plane wakes, the normal stress $\left\langle u^{\prime} u^{\prime}\right\rangle$ is produced by the shear stress $\left\langle u^{\prime} v^{\prime}\right\rangle$. The turbulent kinetic energy is then redistributed via pressure fluctuations from $\left\langle u^{\prime} u^{\prime}\right\rangle$ towards $\left\langle v^{\prime} v^{\prime}\right\rangle$ and $\left\langle w^{\prime} w^{\prime}\right\rangle$.

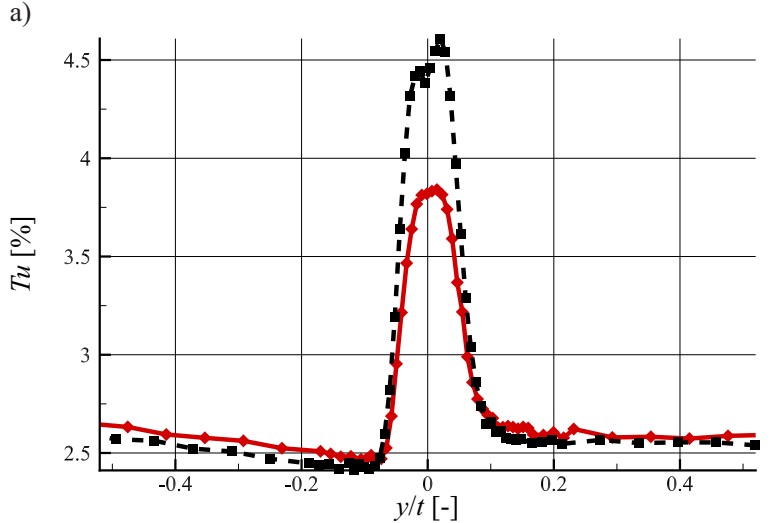

b)

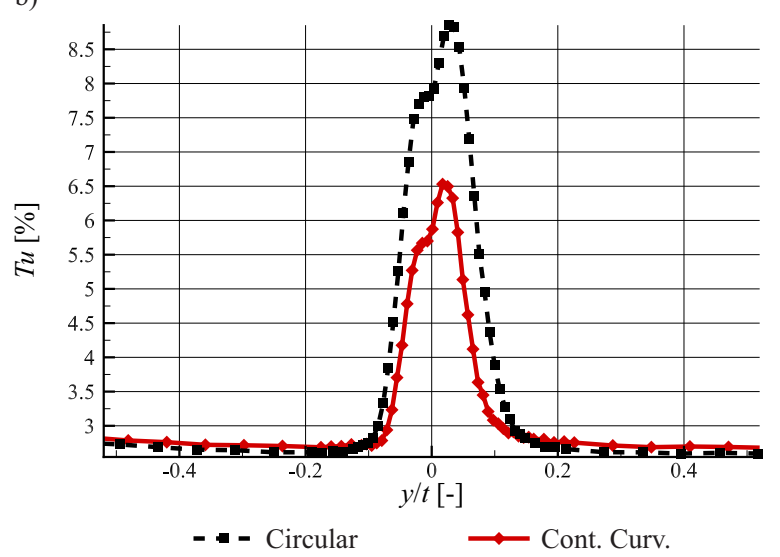

Fig. 18: Turbulence intensity at wake midspan for continuous curvature and circular leading edge. a) $i=0^{\circ}$, b) $i=5^{\circ}$

The measurements confirm the theory because the most apparent difference in the wake region between both configurations is that the normal shear stress $\left\langle u^{\prime} u^{\prime}\right\rangle$ has a different course and magnitude. The circular leading edge possesses two local maxima in $\left\langle u^{\prime} u^{\prime}\right\rangle$, which result from the profile boundary layers of suction and pressure side. In contrast, the continuous curvature configuration possesses only one maximum in $\left\langle u^{\prime} u^{\prime}\right\rangle$. Furthermore, the magnitude of both spikes $\left\langle u^{\prime} u^{\prime}\right\rangle$ is twice as high as for the corresponding positions of the continuous curvature leading edge configuration. Due to the coupling with $\left\langle u^{\prime} u^{\prime}\right\rangle$, the shear stress $\left\langle u^{\prime} v^{\prime}\right\rangle$ is also scaled by a factor of about two for the circular leading edge. On the contrary, there are hardly any differences in $\left\langle v^{\prime} v^{\prime}\right\rangle$ and $\left\langle w^{\prime} w^{\prime}\right\rangle$ between continuous curvature and circular leading edge. The normal stress $\left\langle u^{\prime} u^{\prime}\right\rangle$ is therefore the main reason for the difference in turbulence intensity (Fig. 18). It can be stated that the two leading edges lead to different turbulence production across the profile, and therefore, the turbulence structure varies in the wake.

\section{CONCLUSION}

In this study, an experimental investigation was carried out on three different leading edge geometries at high subsonic conditions. The aim was to verify that a continuous curvature leading edge performs better in respect of losses and working range than conventional leading edges at high subsonic flow conditions. The overall performance showed reductions in the loss coefficient by $15.4 \%$ compared to the circular and $3.1 \%$ compared to the elliptical leading edge. Even though this is only half of the loss reduction presented for low-speed applications in Goodhand [1] and Wheeler [5], the improvements are significant. Future work should investigate this discrepancy in detail. Further loss reduction was found at off-design incidence for both negative and positive directions. Compared to the circular leading edge, the continuous curvature leading edge reduced 
a)

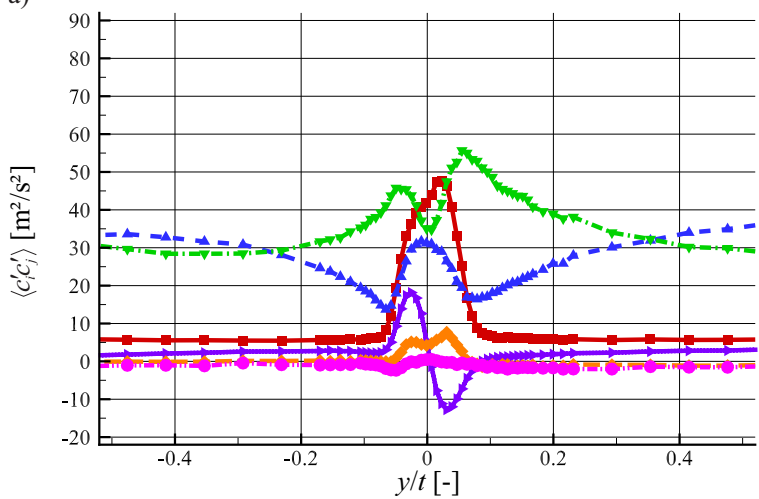

b)

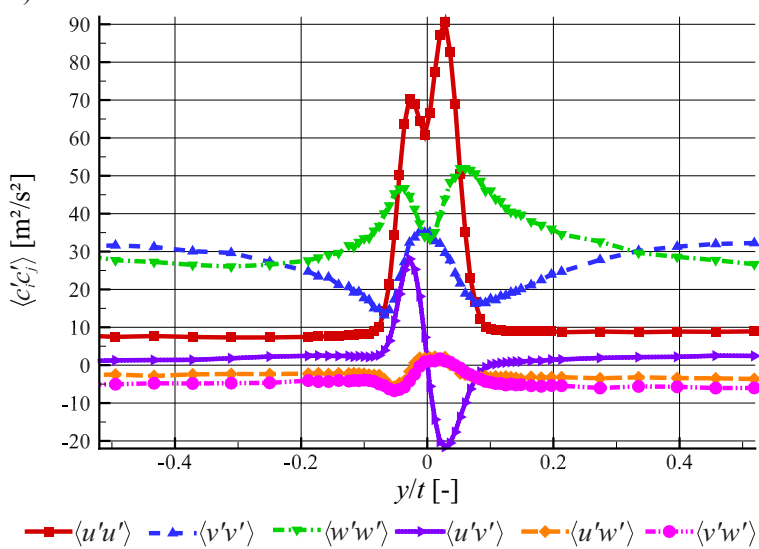

Fig. 19: Reynolds stresses at wake midspan and $i=0^{\circ}$. a) Continuous curvature leading edge, b) circular leading edge

the losses by $45.7 \%$ at $i=-5^{\circ}$ and $40.2 \%$ at $i=5^{\circ}$. Using a loss breakdown into suction and pressure side losses and detailed analysis of the profile wakes, a different loss behavior was identified for the different leading edge geometries. The breakdown showed that both suction side and pressure side contribute to the overall loss, but the ratio differs between the configurations. Given the relatively small dimensions of the airfoils, it was not possible to place pressure taps on the leading edge. However, indications were found for pressure spikes in the vicinity of the circular and elliptical leading edges. The analysis of the turbulence in the wake revealed that the boundary layers already differ considerably at design incidence.

In general, the study strongly suggests the application of continuous curvature leading edges to compressor airfoils. Besides the loss reduction and working range improvement, the outlet flow angle changes less with increasing incidence and the turbulence intensity in the wake decreases. With regard to multi-stage compressors, this is likely to generate further loss reduction, since the inlet flow of stages downstream improves due to smaller incidence variation. From an MRO perspective, the optimized leading edge promises benefits in terms of blade repair. The increase in loss coefficient is more considerable between elliptical and circular leading edges than for continuous curvature and elliptical leading edge, even though the latter combination reveals a stronger decrease in leading edge length.

\section{ACKNOWLEDGEMENTS}

The authors gratefully acknowledge IHI Corporation for permission to publish this paper. Furthermore, the authors wish to thank Mr. Christian Hösgen for providing a comprehensive collection of scripts for pressure and hot-wire probe evaluation.

\section{REFERENCES}

\section{References}

[1] Goodhand, M., and Miller, R., 2011, "Compressor Leading Edge Spikes: A New Performance Criterion", ASME Journal of Turbomachinery, Vol. 131, pp. 1-8.

[2] Goodhand, M., 2010, "Compressor Leading Edges", PhD Thesis, University of Cambridge. p. 2.

[3] Carter, M., 1961, "Blade Profiles for Axial Flow Fans, Pumps and Compressors, Etc.", Proceedings of the Institution of Mechanical Engineers, Vol. 175, pp. 775 - 806.

[4] Walraevens, R., and Cumpsty, N., 1991, "Leading Edge Separation Bubbles on Turbomachinery Blades", Proceedings of ASME Turbo Expo 1991, 93-GT-91.

[5] Wheeler, A., Sofia, A., and Miller, R., 2009, "The Effect of Leading-Edge Geometry on Wake Interactions in Compressors", ASME Journal of Turbomachinery, Vol. 133, pp. 1-8.

[6] Zhang, W., Zou, Z., and Ye, J., 2012, "Leading-edge redesign of a turbomachinery blade and its effect on aerodynamic performance", Applied Energy, Vol. 93, pp. 655 - 667.

[7] Song, Y., Gu, C., and Xiao,Y., 2014, "Numerical and Theoretical Investigations Concerning the Continuous-Surface-Curvature Effect in Compressor Blades", Energies, Vol. 7(12), pp. 8150 8177.

[8] Tain, L., and Cumpsty, N. A., 2000, "Compressor blade leading edges in subsonic compressible flow", Proceedings of the Institution of Mechanical Engineers, Part C: Journal of Mechanical Engineering Science, Vol. 214, pp. 221 - 242.

[9] Li, L., and Liu, H., 2019, "The Analysis of Leading Edge Deformations on Turbomachinery Blades", Energies, Vol. 12(4), p. 736.

[10] Winter, K., 2016, "Einfluss einer Mehrfachwelligkeit auf die Aerodynamik eines sub- und transsonisch umströmten, ebenen Verdichtergitters", PhD Thesis, RWTH Aachen University.

[11] Winter, K., Hartmann, J., Jeschke, P., and Lahmer, M., 2013 , "Experimental and Numerical Investigation of Streamwise Surface Waviness on Axial Compressor Blades", Proceedings of ASME Turbo Expo 2013, GT2013-95983.

[12] Parvizinia, M., 1996, "Einfluss der Filmkühlung auf die Aerodynamik von Turbinenschaufeln", PhD Thesis, RWTH Aachen University.

[13] Rona, A., Paciorri R., and Geron, M., 2006, "Design and Testing of a Transonic Linear Cascade Tunnel With Optimized Slotted Walls", ASME Journal of Turbomachinery, Vol. 128, pp. 26-27.

[14] Parvizinia, M., and Salchow, K., 1993, "Verfahren zur Korrektur des Gradientenfehlers bei Messungen mit pneumatischen Mehrlochsonden", Technical Report, TM93-10, Institute of Jet Propulsion and Turbomachinery, RWTH Aachen University.

[15] Poensgen, C., and Gallus, H. E., 1989, "Ein Kalibrierverfahren für Mehrsensorhitzdrahtsonden". Technical Report, TM-89-02, Institute of Jet Propulsion and Turbomachinery, RWTH Aachen University, pp. 1-41.

[16] Hösgen, C., Behre, S., Hönen, H., and Jeschke, P., 2016 “Analytical Uncertainty Analysis for Hot-Wire Measurements", Proceedings of ASME Turbo Expo 2016, GT2016-56623.

[17] Schlichting, H., Gersten, K., 2017, "Boundary-Layer Theory", Springer-Verlag, Berlin, Heidelberg, pp. 519-556.

[18] Hoeger, M., Schmidt-Eisenlohr, U., Estrada Gomez, S., Sauer, H., and Müller, R., 2002, "Numerical simulation of the influence of a fillet and a bulb on the secondary flow in a compressor cascade", TASK Quarterly 6 No 1 (2002) pp. 25-37. 
[19] Harbecke, U., 2001, "Aerodynamische Wirkung fertigungsbedingter technischer Rauheiten und Geometriefehler an gefrästen Turbinenschaufeln", $P h D$ Thesis, Leibniz University Hannover, pp. 17-19.

[20] Song, B., and Ng, W.F., 2007, "The role of AVDR in linear cascade testing", Journal of Aerospace Power, Vol. 22(6), pp. 933-944.

[21] Batchelor, G.K., 1953, "The theory of homogeneous turbulence”, Cambridge University Press, Cambridge, pp.68-75. 